\title{
Development of a flood damage model for urban drainage networks
}

\author{
Alice Gallazzi ${ }^{1}$, Daniela Molinari ${ }^{1}$, Francesco Ballio ${ }^{1}$, and Anna Rita Scorzini ${ }^{2}$ \\ ${ }^{1}$ Politecnico di Milano, Department of Civil and Environmental Engineering, Piazza Leonardo da Vinci 32, 20133, Milano, Italy \\ ${ }^{2}$ University of L'Aquila, Department of Civil, Environmental and Architectural Engineering, Via Gronchi 18, 67100, L'Aquila, Italy
}

\begin{abstract}
A thorough understanding and assessment of flood damage to network infrastructures is fundamental to assist both policy makers and managing authorities in mitigation and restoration actions against inundations and, consequently, in increasing the resilience of the territories at risk. This research work focuses on the estimation of potential impacts of floods on urban drainage systems, by proposing a general methodology that can be adapted to other typologies of networks. The method consists in the development of damage-dysfunction matrices, as proposed by Eleutério et al. (Nat. Hazards Earth Syst. Sci., 13, 983-998, 2013), for drainage systems, by adopting an expert-based approach. These matrices allow analysing physical, systemic and functional vulnerability of each component of the network under investigation and, therefore, identifying the potential transfer of dysfunctions between the different components. Regarding this last point, a hierarchy description of the network was developed, by means of an ad-hoc methodology, in order to assign a systemic vulnerability degree to each component, hence helping the managing authority to prioritize recovery actions in case of emergency. Nonetheless, by identifying the number and types of users (i.e. residents, businesses, institutions) connected to each sewage pipe, the potential adverse consequences of sewerage's disruptions for society are investigated as well. As an example, the model has been implemented on the sewerage system in the municipality of Parma, Northern Italy, by using the Baganza River Flood in October 2014 as a case study in support of the work.
\end{abstract}

\section{Introduction}

Critical infrastructures are fundamental for the functioning of a society and its economy as they provide different commodities and essential services, and ensure the transport of people and goods. Infrastructures have the fundamental characteristics of systems because they group elements dynamically correlated to each other and organised as a function of an objective (Bouchon, 2006; Narbonne, 2005). Moreover, all such systems are strongly interrelated as well. Thus, the analysis of damage to networks because of a flood, or any other natural disaster, is not an easy task. In the literature on flood damage modelling, networks have received less attention than other exposed sectors. Specifically, few effective tools for a thorough assessment of networks vulnerability to floods are yet available (Merz et al., 2010). The consequences of such a shortage are manifold. Firstly, there is a partial overview of expected damages on a specific region and, thus, an ineffective risk management, which is typically focused on reduction of only measurable damage components. In addition, there is a partial lack of knowhow by managing authorities to prevent and reduce flood impacts on networks. Hence, the need arises to develop a flood damage model for network infrastructures that could support both policy makers and systems managers in mitigation and restoration actions against inundations and, furthermore, assist civil protection authorities in emergency management operations.

This research work focuses on the estimation of potential impacts of floods on urban drainage systems, by proposing a general methodology that can be adapted to other typologies of networks. The method consists in the development of damage-dysfunction matrices, as proposed by Eleutério et al. (2013), for drainage systems, by adopting an expert-based approach. These matrices allow analysing physical, functional and systemic vulnerability of each component of the network under investigation and, therefore, identifying the potential transfer of dysfunctions between the different components. Regarding this last point, a hierarchy description of the network was developed in order to assign a systemic vulnerability degree to each component, and to identify users connected to each sewer.

As an example, the model has been implemented on the sewerage system in the municipality of Parma, Northern Italy, by using the Baganza River Flood in October 2014 as a case study in support of the work. From a phenomenological point of view, the work is focused only on fluvial floods, without considering pluvial floods caused by deficiencies of sewerage systems. 
Both managing authorities and society can benefit from such a model. On the one hand, a comprehensive knowledge of the potential flood impacts on networks helps managing authorities not only to best organise recovery actions in case of emergency, but also to identify the weakest components and, therefore, define the intervention priorities in time of peace. On the other hand, the analysis of the potential adverse consequences of service disruptions for society and environment support the civil protection operations during emergency phase.

The paper is organised as follows. The method proposed by Eleutério et al. (2013) and the methodology developed for urban drainage systems are first presented in Sect. 2. Section 3 presents the implementation of the model to the case study. Finally, in Sect. 4, critical issues from the research work and considerations of future developments are discussed.

\section{Method for evaluating the potential flood damage to network infrastructures}

As anticipated in the introduction, sewerage vulnerability to floods was analysed by following the damage-dysfunction matrices approach, developed by Eleutério et al. (2013), and schematically represented in Fig. 1. Such matrices must be developed for each component of a network and each of them is organised in six charts:

- Chart I provides a quantitative description of the circumstances that may cause (physical) damage and/or dysfunction to the component analysed; each component of the network is vulnerable to external hazards by direct contact with floodwater, or by the transfer of vulnerability from other components. This chart requires a full characterisation of the structure of the network.

- $\quad$ Chart II and III provide qualitative descriptions of the potential types of damage and dysfunction to the component analysed. These charts require data on direct physical damages and dysfunctions of the component under investigation.

- Chart IV identifies which components from the same network and from correlated networks can be impacted by the damage/dysfunction of the given component. This chart requires data on the outage of the analysed network or outages of other interlinked infrastructures (i.e. systemic vulnerability).

- $\quad$ Chart V describes the different actions necessary to ensure the operation or repair damage/dysfunction of the given component. This chart requires data on types of interventions.

- Chart VI summarises time and monetary values of the intervention actions identified at the previous chart. This chart requires data on times and costs of interventions.

Thus, the damage-dysfunction matrices tool has the main advantage of describing the full range of impacts that can be suffered by a system, but this results in the need of a huge amount of data.

\subsection{Methodological approach for urban drainage systems}

A thorough literature review and the analysis of the case study highlighted lack of empirical data on potential damages to urban drainage systems in case of flood. Such a lack might be due to the confidentiality of data of responsibility of private networks managers, or to the actual invulnerability of sewerage to inundation phenomena. Consequently, the damage-dysfunction matrices were developed by adopting a synthetic approach based on the expert investigation of causes and consequences of damage, also known as "what-if analysis" (Dottori et al., 2016).

Lack of observed damage data and of a hydraulic model of the sewerage system of Parma did not enable us to describe the factors/circumstances causing damage and dysfunction in quantitative terms but only in qualitative ones. Therefore, Charts I, II and III proposed by Eleutério et al.

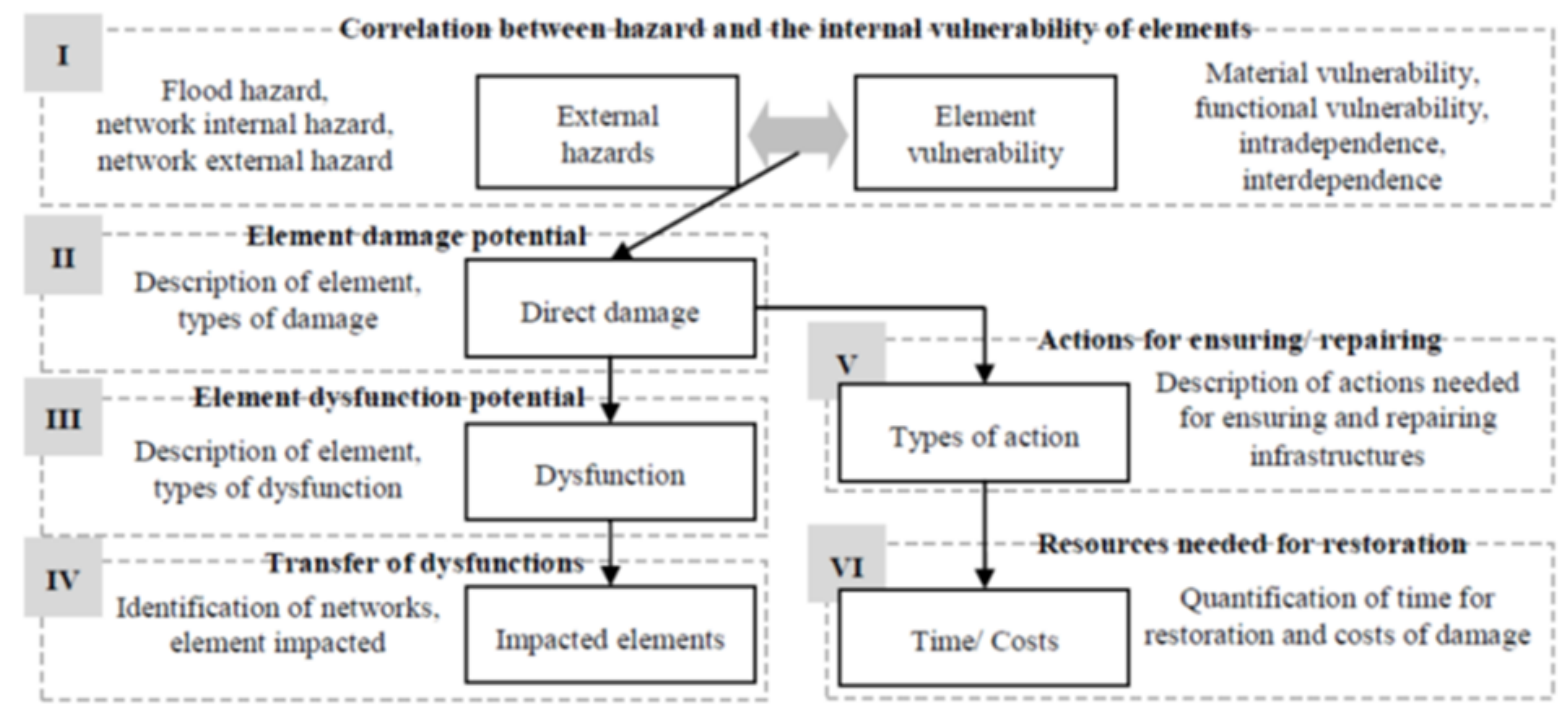

Figure 1. Structure of damage-dysfunction matrices (Eleutério et al., 2013). 
(2013) were grouped in only one matrix for each network component that provides an overall qualitative description of damage mechanisms, physical, functional and systemic damages, as well as explicative hazard and vulnerability parameters. Hereinafter, they are referred to as "physical and functional vulnerability matrices".

Then, a methodology for the systemic vulnerability assessment (Chart IV) was developed in order to understand how potential damages and dysfunctions to a specific component could spread throughout the network and furthermore how disruptions of sewerage could affect users.

With regard to the interconnections with other network infrastructures, literature investigation and discussions with experts indicated that urban drainage systems are strongly dependent on the electricity grid, because a power failure may result in outages of some essential sewerage components, such as pumping stations, increasing their functional vulnerability. This aspect is included in the physical and functional matrices. Conversely, it seems unlikely that outages of sewerages could affect other infrastructures, except for flooding of road networks in case of heavy rain (but pluvial floods are not evaluated in this research work) and the potential effects on wastewater treatment plants. Indeed, during flood events, combined sewage and surface runoff flows may exceed the maximum flow rate of the system, or the capacity of the sewage treatment plant, causing serious water pollution problems. In the former case, relief systems cause discharges containing human and industrial waste to flow directly into rivers, streams or other bodies of water with negative environmental consequences; in the second case, the excess amount and pollutants concentration of the flows sent to treatment plants may cause severe damages to plants themselves. Although this is an important matter to be examined in favour of more comprehensive assessments, the potential impacts on wastewater treatment plants were not within the objectives of this study.

Lastly, Chart V and VI by Eleutério et al. (2013) have not been developed because the definition and the responsibility of mitigation and repair actions lie within networks managers.

\subsection{Conceptual development of physical and functional vulnerability matrices}

A typical urban drainage network is made up of linear components, i.e. sewers and channels, and a series of punctual elements: pumping stations, wastewater treatment plants, building and storm drains, manholes, inspection chambers, spillways, valves, gauges. We decided to derive only two vulnerability matrices with the support of experts: one for sewers and the other for pumping stations. All the other punctual components were included in the matrix for sewers as additional physical characteristics which increase or reduce sewer vulnerability (systemic vulnerability).

\section{$\underline{\text { Physical and functional vulnerability matrix for sewers }}$}

The matrix in Fig. 2 shows the potential damage mechanisms for sewers in case of flood, that were identified in discussion with experts; the different types of physical, functional and systemic damages depend on hazard parameters related to the event, physical/structural characteristics of sewers and the possible presence of additional components (i.e. inspection chambers and spillways) which may alter the sewer vulnerability.

As an example, the damage mechanism in the first line corresponds to the over pressure of the sewerage due to incoming river water from spillways; this may result in possible damages to the interested sewer (physical vulnerability), a reduced functioning of it (functional vulnerability), a decreased storage capacity of upstream network, and manholes covers opening with consequent surface flooding (systemic vulnerability). The overflow occurs when the water depth in rivers exceeds the spillways threshold and its hydraulic head passes that in sewers. Thus, this phenomenon depends on water depth in river and hydraulic head in sewerage from the hazard point of view and more likely occurs in sewers with the following vulnerability characteristics: presence of a spillway, proximity to a waterway, medium-high installation depth (greater difference between pipes installation depth and river water level), small diameter (more pressure).

All the data identified as necessary to the flood vulnerability assessment for sewers are summarised in Table 1.

\begin{tabular}{|c|c|}
\hline \multicolumn{2}{|l|}{ Hazard parameters } \\
\hline \multicolumn{2}{|l|}{ Hydraulic head in sewers } \\
\hline \multicolumn{2}{|l|}{ Flow rate in sewers } \\
\hline \multicolumn{2}{|l|}{ Surface water depth } \\
\hline \multicolumn{2}{|l|}{ Surface inundation duration } \\
\hline \multicolumn{2}{|l|}{ Hydraulic head in river } \\
\hline \multicolumn{2}{|l|}{ Water depth in river } \\
\hline \multicolumn{2}{|l|}{ Flow velocity in river } \\
\hline \multicolumn{2}{|l|}{ Solid transport in river } \\
\hline \multicolumn{2}{|l|}{ Groundwater level } \\
\hline \multicolumn{2}{|l|}{ Vulnerability parameters } \\
\hline \multirow{2}{*}{$\begin{array}{l}\text { Physical characteristics of } \\
\text { sewers }\end{array}$} & Material \\
\hline & Diameter \\
\hline \multirow{3}{*}{$\begin{array}{l}\text { Structural characteristics of } \\
\text { sewers }\end{array}$} & Slope \\
\hline & Installation depth \\
\hline & $\begin{array}{l}\text { Distance from } \\
\text { waterways }\end{array}$ \\
\hline \multirow{3}{*}{$\begin{array}{l}\text { Presence of punctual } \\
\text { components }\end{array}$} & Spillway \\
\hline & Inspection chamber \\
\hline & $\begin{array}{l}\text { Crossing structure of } \\
\text { rivers }\end{array}$ \\
\hline
\end{tabular}

Table 1. Data for physical and functional vulnerability assessment of sewers in case of flood. 
Budapest University of Technology and Economics (BME)

\begin{tabular}{|c|c|c|c|c|c|c|c|c|}
\hline 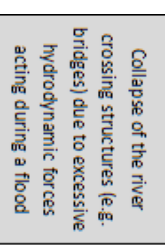 & 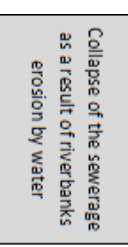 & 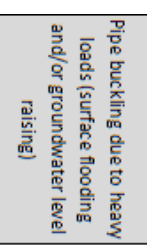 & 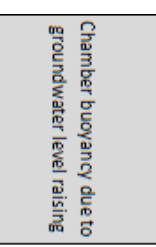 & 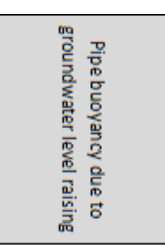 & 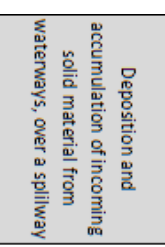 & 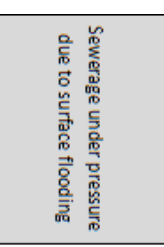 & 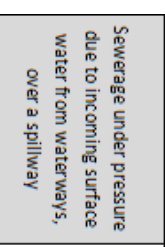 & 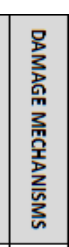 \\
\hline 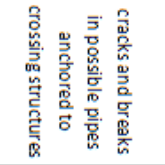 & 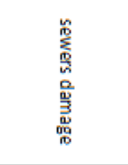 & 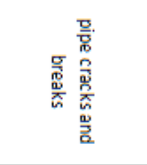 & 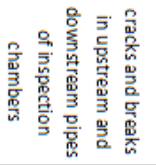 & 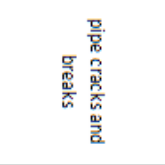 & & 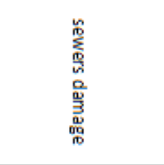 & 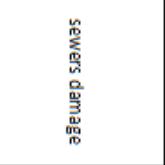 & 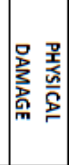 \\
\hline & & & & & 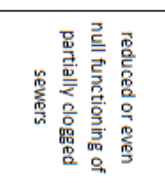 & 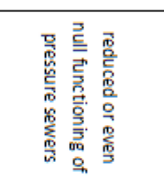 & 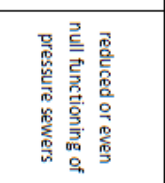 & 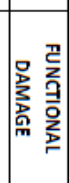 \\
\hline & & 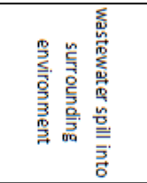 & & 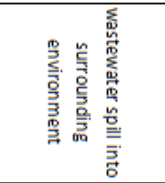 & 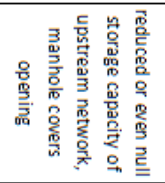 & 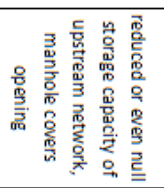 & 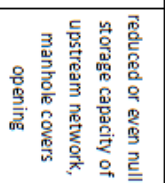 & 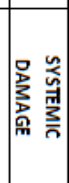 \\
\hline 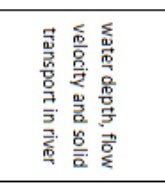 & 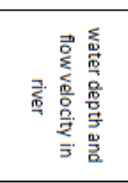 & 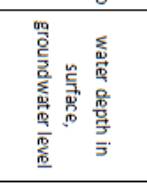 & 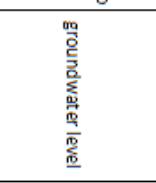 & 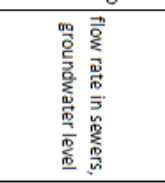 & 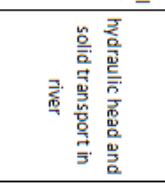 & 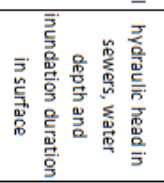 & 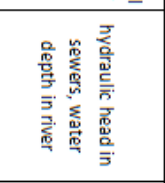 & 俤 \\
\hline & & 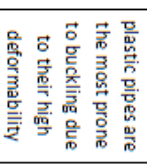 & & 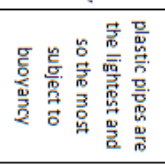 & & & & 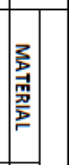 \\
\hline & & & & 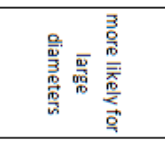 & & 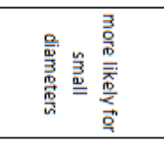 & 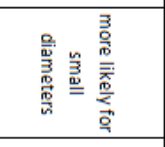 & 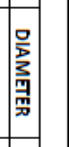 \\
\hline & & & & & 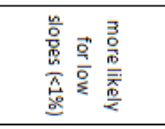 & & & $\mid$ \\
\hline & 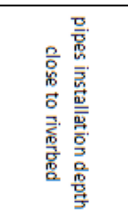 & 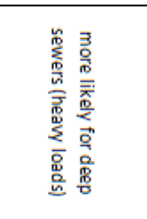 & 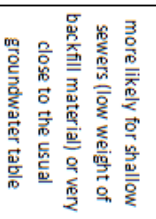 & 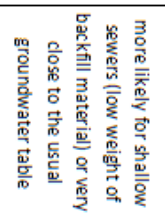 & 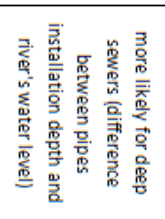 & & 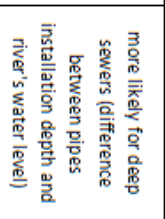 & $\mid$ \\
\hline 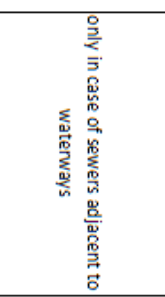 & 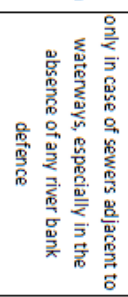 & & & & 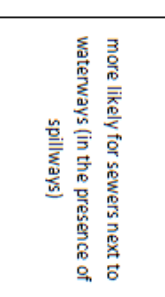 & & 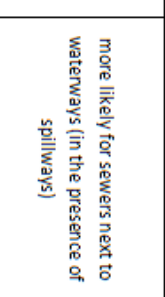 & 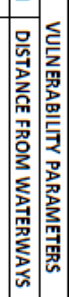 \\
\hline & & & & & 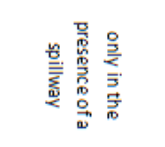 & & 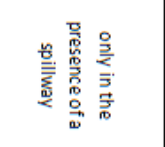 & 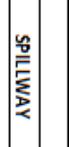 \\
\hline & & & 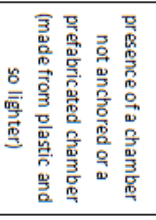 & & & & & $\mid$ \\
\hline 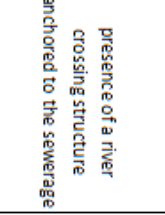 & & & & & & & & $\mid$ \\
\hline
\end{tabular}

Figure 2. Physical and functional vulnerability matrix for sewers. 


\section{Physical and functional vulnerability matrix for pumping} stations

The matrix in Fig. 3 shows the potential flood damages to pumping stations of a sewage system that were identified by consultation with experts; such for sewers, the different types of physical, functional and systemic damages depend on both hazard parameters related to the event and physical and systemic characteristics of the plants. In particular, we would point out that a dysfunction of pumping plants always results in a reduced storage capacity of the upstream network.

For example, the damage mechanism in the first line corresponds to swift and long duration flooding of a pumping station that may cause electricity outages and thus interruptions in the pumping system; this may produce damages to the pumping system (physical vulnerability), an interruption of water flow in correspondence of the pumping station (functional vulnerability) and a reduction of storage capacity of the upstream network (systemic vulnerability). This phenomenon depends on water depth and inundation duration in the pumping station from the hazard point of view, and only occurs in stations that are still not equipped with submersible pumps in vulnerability terms. However, this circumstance is unlikely since sewage pumping is normally done by submersible pumps.

All the data identified as necessary to the flood vulnerability assessment for sewage pumping stations are collected in Table 2.

\begin{tabular}{|l|}
\hline Hazard parameters \\
\hline Water depth in pumping station \\
\hline Inundation duration in pumping station \\
\hline Solid transport in pumping station \\
\hline Vulnerability parameters \\
\hline Type of pumps (i.e. submersible or not) \\
\hline $\begin{array}{l}\text { Installation configuration of electric components of the } \\
\text { system (i.e. watertight or not) }\end{array}$ \\
\hline Connection with power grid \\
\hline
\end{tabular}

Table 2. Data for physical and functional vulnerability assessment of sewage pumping stations in case of flood.

\subsection{Systemic vulnerability of the network}

An ad hoc-methodology was developed for the hierarchy description of the network ("hierarchy method" in the following) in order to investigate the potential transfer of damages and dysfunctions between the different components, as well as the potential adverse consequences of system disruptions for society. The method consists in assigning a systemic vulnerability degree to each segment of the network, that is to each sewage pipe, based on the following steps:

1) Assignment of two attributes to each segment: the number of nodes (defined as "order" of the segment) and the number of external segments (i.e. unrelated to any upstream segment) preceding the segment under consideration; each node corresponds to either a confluence of two pipes or a pumping station. This first hierarchy, schematically depicted in Fig. 4, is carried out starting from the external pipes (zero-order segments) towards the treatment plant.

2) Assignment to each segment of a third attribute, that was introduced in order to take into account of possible mesh portions of the network: the number of "fictitious nodes" preceding the segment under consideration. In fact, while for the common segments with a tree structure each node corresponds to a flow

\begin{tabular}{|c|c|c|c|c|c|c|c|}
\hline \multirow{2}{*}{ DAMAGE MECHANISMS } & \multirow{2}{*}{ PHYSICAL DAMAGE } & \multirow{2}{*}{ FUNCTIONAL DAMAGE } & \multirow{2}{*}{ SYSTEMIC DAMAGE } & \multirow{2}{*}{ HAZARD PARAMETERS } & \multicolumn{3}{|c|}{ VULNERABILITY PARAMETERS } \\
\hline & & & & & TYPE OF PUMPS & \begin{tabular}{|l|} 
INSTALLATION CONFIGURATION \\
\end{tabular} & CONNECTION WITH ELECTRICAL GRID \\
\hline $\begin{array}{l}\text { Block of the pumping system } \\
\text { due to electricity } \\
\text { interruptions as a result of } \\
\text { pumping station flooding }\end{array}$ & $\begin{array}{l}\text { possible damages to } \\
\text { the pumping system }\end{array}$ & $\begin{array}{c}\text { water flow interruption in } \\
\text { correspondence with } \\
\text { pumping station }\end{array}$ & $\begin{array}{l}\text { reduced or even null } \\
\text { storage capacity of } \\
\text { upstream network }\end{array}$ & $\begin{array}{c}\text { water depth and } \\
\text { inundation duration in } \\
\text { pumping station }\end{array}$ & $\begin{array}{c}\text { only in stations where } \\
\text { pumps are not } \\
\text { submersible }\end{array}$ & & \\
\hline $\begin{array}{l}\text { Block of the pumping system } \\
\text { due to interrumptions in } \\
\text { power supply as a result of } \\
\text { damages to electrical grid }\end{array}$ & & $\begin{array}{c}\text { water flow interruption in } \\
\text { correspondence with } \\
\text { pumping station }\end{array}$ & $\begin{array}{l}\text { reduced or even null } \\
\text { storage capacity of } \\
\text { upstream network }\end{array}$ & & & & $\begin{array}{l}\text { the dependency on electrical grid may } \\
\text { increase functional vulnerability of } \\
\text { sewerage's pumping stations }\end{array}$ \\
\hline $\begin{array}{l}\text { Block of the pump impeller } \\
\text { due to an excessive } \\
\text { deposition of solid material in } \\
\text { pumping station }\end{array}$ & $\begin{array}{c}\text { damage to the pump } \\
\text { impeller and possible } \\
\text { damages to the other } \\
\text { components }\end{array}$ & $\begin{array}{c}\text { water flow interruption in } \\
\text { correspondence with } \\
\text { pumping station }\end{array}$ & $\begin{array}{l}\text { reduced or even null } \\
\text { storage capacity of } \\
\text { upstream network }\end{array}$ & $\begin{array}{l}\text { solid transport in } \\
\text { pumping station }\end{array}$ & for any type of pumps & & \\
\hline $\begin{array}{l}\text { Damages to electric panel, } \\
\text { transformer and } \\
\text { control/regulation devices }\end{array}$ & $\begin{array}{c}\text { damages to the electric } \\
\text { components of the } \\
\text { system }\end{array}$ & $\begin{array}{c}\text { water flow interruption in } \\
\text { correspondence with } \\
\text { pumping station }\end{array}$ & $\begin{array}{l}\text { reduced or even null } \\
\text { storage capacity of } \\
\text { upstream network }\end{array}$ & $\begin{array}{l}\text { water depth and } \\
\text { inundation duration in } \\
\text { pumping station }\end{array}$ & & $\begin{array}{l}\text { only in stations where electrical } \\
\text { system is not watertight }\end{array}$ & \\
\hline
\end{tabular}

Figure 3. Physical and functional vulnerability matrix for pumping stations. 
convergence, in the mesh portions there are nodes coinciding with a flow separation and for this they are defined as "fictitious nodes" (Fig. 5a). The downstream pipes of a fictitious node are regarded as zero-order segments because of path redundancy: in the event of dysfunction in one pipe, the flow can proceed in the other. Nevertheless, it is important to mark the presence of fictitious nodes downstream of mesh portions for a correct hierarchy of the network, as shown in Fig. 5b.

3) Calculation of the total number of segments that depend on the segment under consideration by using the following formula:

$$
\begin{gathered}
\text { total segments }=\text { order }+ \text { external segments }-1 \\
+ \text { fictitious nodes } * 2
\end{gathered}
$$

4) Identification and assignment to each segment of the number of connected residents, businesses and institutions (hospital, schools, etc.) in order to evaluate the potential adverse consequences of damages and dysfunctions of sewerage for different types of users.

In conclusion, the hierarchy method consists in assigning seven attributed to each sewage pipe: order/nodes, external segments, fictitious nodes, total segments, residents, businesses, institutions. This provides a comprehensive assessment of the systemic vulnerability of urban drainage systems which benefit both managing authorities and society.

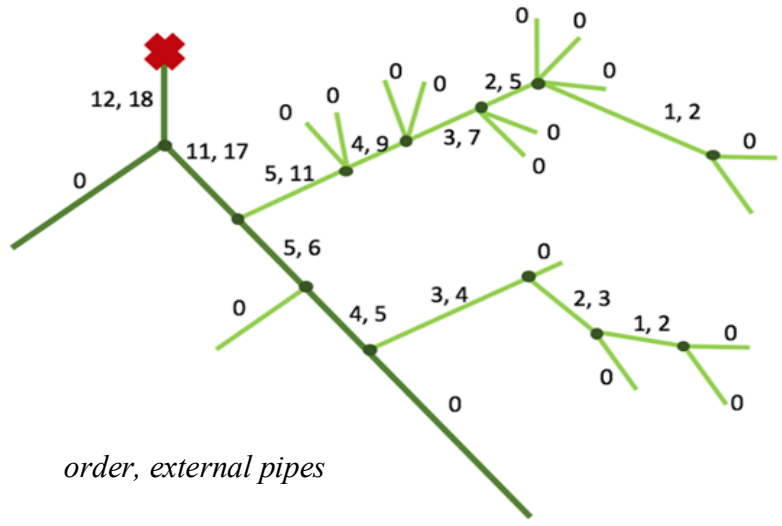

Figure 4. Diagram of the first step of the network hierarchy method: assignment of the order and the number of external pipes to each segment.

\section{Case study}

The investigated context is the municipality of Parma, Northern Italy, which on 13 October 2014 was hit by a flood caused by the overflow of the Baganza River. The flood did not cause severe damages to urban drainage system, except for the accumulation of silt and mud in some sewers, that were cleaned up promptly.

The available information for the implementation of the model to the case study is reported in Table 3.

First of all, we analysed the structure and composition of the network based on the vector database of the sewerage of Parma. This is largely a combined sewerage, designed to simultaneously collect surface runoff and sewage water in a shared system; but some portions have separate sanitary sewers, that transport sewage alone, and separate storm drains, designed to convey surface runoff directly to surface waters. The structure of the network is mainly made up of concrete and plastic pipes ranging from $60 \mathrm{~mm}$ to $8 \mathrm{~m}$ in diameter. In addition, the system includes the following punctual elements: regulation components (about 30 pumping stations, 90 spillways, 8 check valves), inspection chambers and storm drains. The sewers carry wastewater to two main treatment plants, named "Ovest" and "Est", and some smaller plants.
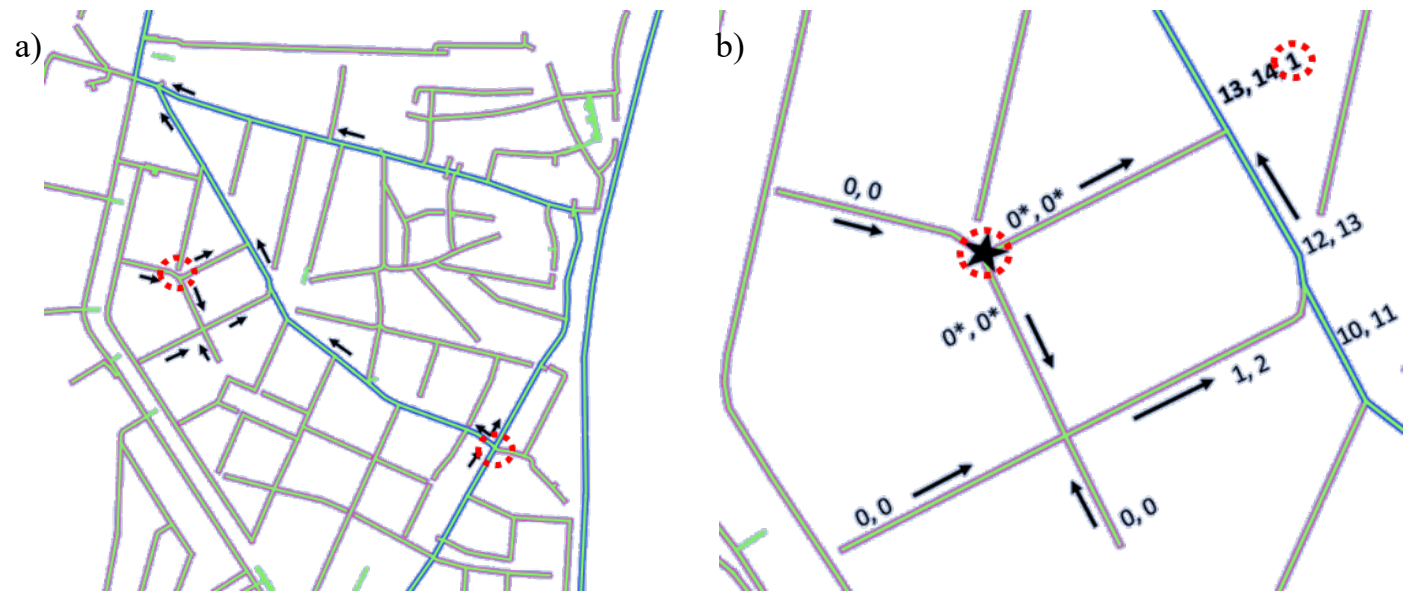

Figure 5. Second step of network hierarchy method: a) example of mesh portions through the network (fictitious nodes are marked with a red circle); b) diagram of hierarchy structure in correspondence of a mesh portion 


\begin{tabular}{|l|l|}
\hline Data & Source \\
\hline $\begin{array}{l}\text { Vector database of the sewerage } \\
\text { of Parma }\end{array}$ & $\begin{array}{l}\text { Management } \\
\text { authority (Iren } \\
\text { Group) }\end{array}$ \\
\hline $\begin{array}{l}\text { Damages to the sewerage } \\
\text { caused by the Baganza River } \\
\text { Flood in 2014 }\end{array}$ & $\begin{array}{l}\text { Management } \\
\text { authority (Iren } \\
\text { Group) }\end{array}$ \\
\hline $\begin{array}{l}\text { Shapefile of flood extent related } \\
\text { to the Baganza River Flood in } \\
\text { 2014 }\end{array}$ & $\begin{array}{l}\text { Po River District } \\
\text { Authority }\end{array}$ \\
\hline $\begin{array}{l}\text { Shapefile of street numbers of } \\
\text { Parma (with number of residents } \\
\text { and businesses) }\end{array}$ & $\begin{array}{l}\text { Municipality of } \\
\text { Parma }\end{array}$ \\
\hline $\begin{array}{l}\text { Regional topographical database } \\
\text { (buildings, streets, etc.) }\end{array}$ & $\begin{array}{l}\text { Region of Emili- } \\
\text { Romagna }\end{array}$ \\
\hline
\end{tabular}

Table 3. Available data for the implementation of the methodology to the sewage system of Parma.

\subsection{Implementation of the model to the case study}

The model was implemented only to the portion of the sewerage affected by the Baganza River Flood in 2014, that is, the sewers connected to "Ovest" treatment plant. Firstly, we applied the hierarchy method to define the systemic vulnerability degree of each sewer. Regarding information on users, whereas the numbers of residents and businesses connected to each segment were derived from the street numbers shapefile, the number of connected institutions was determined locating and mapping the main institutions (i.e. hospitals, schools, sport centres, police stations) in the area of interest by Google Maps and a regional WebGIS. Hence, around 48.000 residents, 30 businesses and 34 institutions of the municipality of Parma are connected to the examined portion of sewerage.

Secondly, we analysed the physical and functional vulnerability of the sewers under investigation according to the developed matrices and case study flood: we identified the most potentially vulnerable components based on their physical and structural characteristics and the flood extent. After that, on the basis of the systemic vulnerability level of these components, we evaluated the related damage scenarios, in terms of the potential impacts on both society and environment in case of damage or dysfunction. In particular, we studied four scenarios covering all the different damage mechanisms identified in the conceptual model:

- Scenario 1: (physical/functional) damage to a PVC pipe upstream of the flood area

- Scenario 2: (physical/functional) damage to a pipe equipped with a spillway

- Scenario 3: (physical/functional) damage to a PVC pipe in the flood area

- Scenario 4: (physical/functional) damage to a pumping station

Figure 6 highlights the location of the analysed elements along the sewerage and in respect to the flood area.

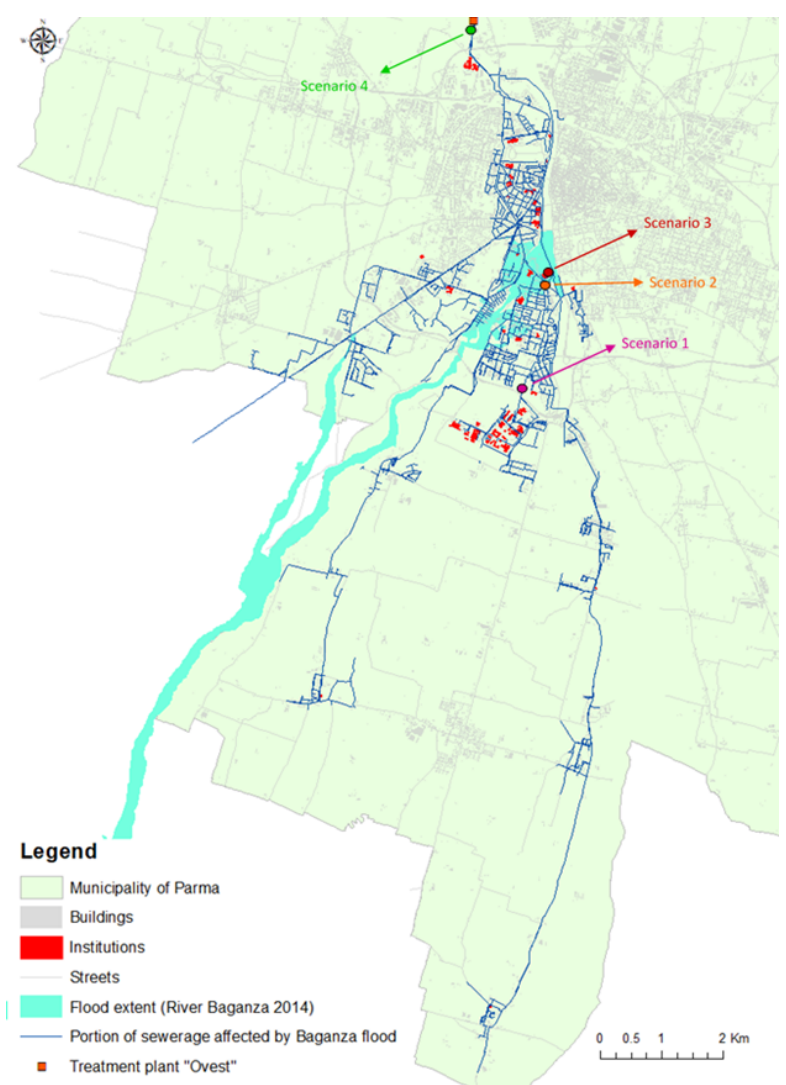

Figure 6. Portion of the sewerage affected by the Baganza River Flood in 2014 and location of the components considered in the four scenarios.

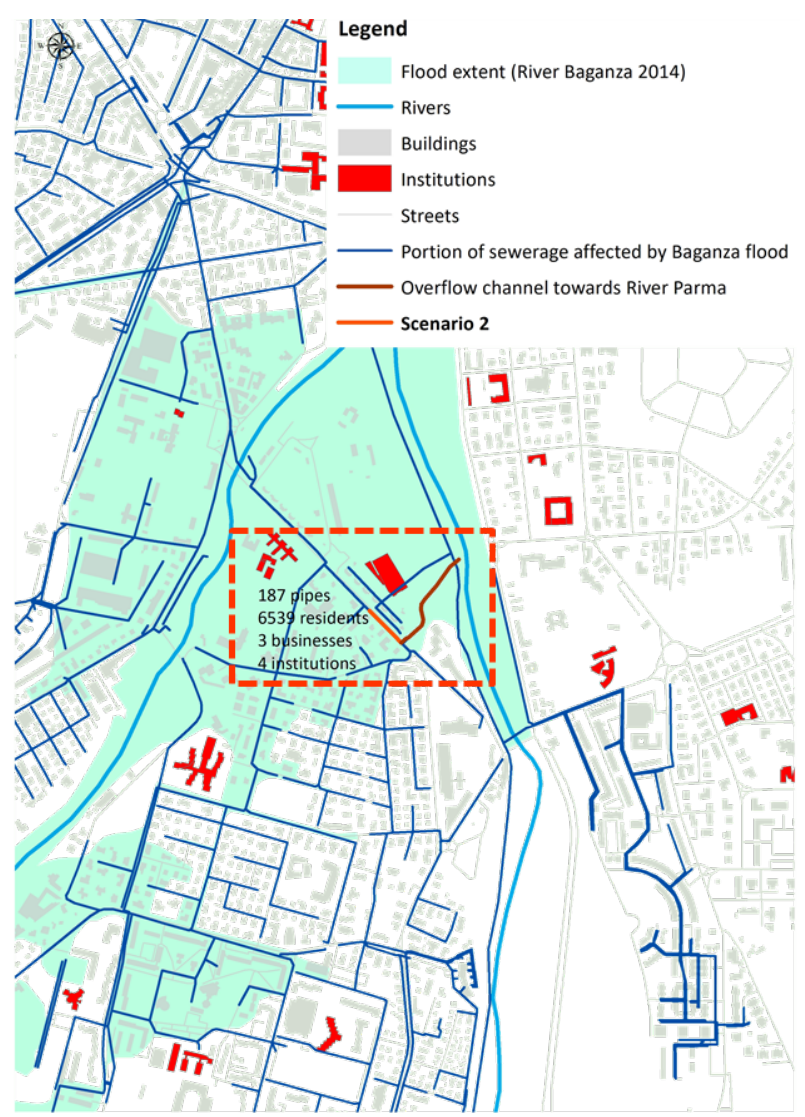

Figure 7. Systemic damage due to physical/functional damage to a sewer equipped with a spillway. 
As an example, Scenario 2 can be explained: physical and/or functional damage to a sewer equipped with a spillway that discharges surface runoff into the Parma stream. According to the flood damage mechanisms defined in the vulnerability matrix for sewers (Fig. 2), this specific pipe might be affected by incoming water and sediments from the stream, causing possible dysfunctions and damages to sewer and reducing its capacity. In systemic terms, as shown in Fig. 7, 187 pipes and 6546 users might be impacted by the outage of the sewer under investigation with major unfavourable consequences for both civil protection authorities in emergency management and network manager in restoration actions. In fact, no overflowing and clog circumstances occurred during the case study flood. The reasons for this could lie in the structural characteristics of the spillway (i.e. slope and installation depth), water depth and solid transport in the stream and hydraulic head in the pipe. The diameter of the overflow channel (600 to $1100 \mathrm{~mm}$ ) was undoubtedly an important factor in the non-occurrence of these phenomena.

\section{Conclusions}

\subsection{Critical analysis of the method}

The matrices developed and implemented in this research work does not provide a quantitative evaluation of the physical and functional vulnerability of urban drainage systems, but a qualitative description, mainly because of a paucity of data. Firstly, it was not possible to define threshold values for hazard and vulnerability parameters causing the different damage mechanisms due to lack of empirical hazard and damage data related to past events. Furthermore, the implementation of the method to the case study was made more complex by the lack of hydraulic modelling of the network and of the Baganza flood in 2014, as well as by insufficient knowledge of the components of the sewage system under investigation. In fact, the vector database of the sewerage of Parma, despite being more detailed than those available for other Italian municipalities, lacks important information about physical, structural and functional characteristics of all the components such as slope and installation depth of sewers. Nevertheless, according to the results from the literature review and discussions with experts, the quantification of the developed matrices would not be advantageous for network managers, since flood damage to urban drainage systems seems to be a rather infrequent phenomenon causing limited restoration costs. On the other hand, the proposed qualitative assessment of the physical and functional vulnerability of the network can be an efficient support for the identification of critical components of the sewerage under routine maintenance. By contrast, in terms of damage to society, the analysis of the systemic vulnerability in the case study indicated how damages to specific elements of the sewerage could significantly impact on users and environment. Thus, a punctual quantitative assessment of systemic vulnerability in correspondence of critical components is highly recommended to define emergency management actions and reduce adverse consequences on society.

Some problems occurred in the implementation of the hierarchy method as well, owing to lack of information on the number of users connected to each sewer. Based on a highly simplifying assumption, we assigned street numbers and related users to the closest pipe. Hence the importance of detailed knowledge of users arises.

\subsection{Future developments}

The methodology developed and implemented for urban drainage systems can potentially be applied and properly adapted to other typologies of network infrastructures for which the quantification of hazard and vulnerability parameters could be even more interesting. Indeed, our investigations of past flood events showed that the impacts on roads, power grids and water supply networks could cause significant damages for both network managers and society.

The hierarchy method can be used to study the systemic vulnerability of any network infrastructure, that is made up of segments and nodes. New physical and functional vulnerability matrices need to be developed to analyse all the potential damage mechanisms for other typologies of networks.

In the prospect of extending this general methodology to other systems, an integrated approach would be advantageous since all the critical infrastructures are closely interconnected in our current society and, as a consequence, disruptions of one service can potentially affect the others.

\section{Acknowledgements}

This work has been funded by Fondazione AMGA, within a private research agreement. Authors acknowledge with gratitude the managing authority of the sewage system in Parma (i.e. Iren Group) for their support in the development of the work.

\section{References}

1. Bouchon, S. (2006). The Vulnerability of Interdependent Critical Infrastructures Systems: Epistemological and Conceptual State-of-the-Art. European Commission, Directorate-General Joint Research Centre, Institute for the Protection and Security of the Citizen, Ispra, Italy

2. Dottori, F., R. Figueiredo, M.L.V. Martina, D. Molinari and A.R. Scorzini (2016). INSYDE: a synthetic, probabilistic flood damage model based on explicit cost analysis. Nat. Hazards Earth Syst. Sci., 16: 2577-2591, doi:10.5194/nhess-16-2577-2016

3. Eleutério, J., C. Hattemer and A. Rozan (2013). A systemic method for evaluating the potential impacts of floods on network infrastructures. Nat. Hazards Earth Syst. Sci., 13: 983-998, doi:10.5194/nhess-13983-2013

4. Merz, B., H. Kreibich and A. Thieken (2010). Review article "Assessment of economic flood damage". Nat. 
FLOODrisk 2020 - $4^{\text {th }}$ European Conference on Flood Risk Management

Hazards Earth Syst. Sci., 10: 1697-1724, doi:10.5194/nhess-10-1697-2010

5. Narbonne, Y. (2005). Complexité et systémique.

Edited by: publication, H.S., Lavoisier, Paris, 2005 